\title{
1. Creative cities in a knowledge society: introduction
}

\section{Marina van Geenhuizen and Peter Nijkamp}

\section{PROMETHEUS VERSUS EPIMETHEUS}

Nowadays there is much talk about the 'knowledge society'. This concept has become rather fashionable and suggests that we live in a new era of human history in which knowledge is the prominent landmark and driver of socioeconomic and technological dynamics. And consequently, we talk about smart regions or cities, smart industries, smart technologies and even about smart knowledge. Clearly, we cannot deny the pervasive importance of knowledge for societal well-being, both locally and globally. But it also ought to be recognized that knowledge generation, acquisition and application have been accepted aspirations in all civilized societies.

Ancient Greek history testifies to the critical importance of knowledge for progress and performance; witness the statement of the influential Greek political philosopher and dramatist Euripides, who once claimed in a period of political turmoil with neighbouring countries - that 'knowledge is more important than a strong arm'. Insight and foresight are indeed critical success factors for well-being and survival. This is clearly reflected in the names of two mythological figures in Ancient Greece, Prometheus and Epimetheus. These were two brothers, of divine origin, who were concerned about the fate of mankind and dared to challenge the ancient gods. The meaning of Prometheus is 'the person who thinks ahead', whereas the meaning of Epimetheus is 'the person who thinks too late'. The two brothers managed to take fire from heaven to bring life into bodies made out of clay. The revenge of Zeus was terrible, as he used Epimetheus as an instrument to introduce many disasters on earth - through Pandora's Box - whereas Prometheus was punished for his cleverness. Apparently, knowledge can be a source of blessings or disasters. Novel knowledge can be a blessing for urban growth in one period but - if outdated - may lead to stagnation and low quality of life in periods that follow.

Also, the period of Enlightenment marked an age where knowledge was seen as a vehicle for solid wisdom and new insights in order to cope with 
the great many challenges for mankind. In our modern world, knowledge is often seen as a source of innovation. The interface of knowledge and innovation is regarded as a critical condition for both technological and societal progress. Knowledge in itself is a necessary but not sufficient condition for further progress in society. Innovation - not only as a way of doing things faster, better and cheaper, but also as a creative mode of thinking and acting (the 'new combinations' à la Schumpeter) - is based on new insights and applications, which help industry and science to gain a strong competitive position. From this perspective, knowledge-intensive and innovation-oriented regions and localities are of utmost importance, as these areas may be seen as the drivers of new initiatives through which existing patterns of business become outdated and are replaced by modern ones that are more fit for purpose. The present volume consists of studies that critically examine policies designed by cities to enable them to become creative knowledge cities, as well as processes and city attributes conceived as key in this development.

\section{CREATIVE KNOWLEDGE CITIES’ POLICIES}

Cities in developed countries have been experiencing a transition to knowledge-based economies since the 1980s. This transition has had enormous consequences for the focus in urban and planning (Carrillo 2006; van Geenhuizen and Nijkamp, 2006; Musterd and Murie, 2010). These consequences, however, are different across the developed world. For example, cities whose economies and societies are primarily shaped by knowledge institutes (mostly a university) have existed for a long time. From the fifteenth century onward university cities such as Oxford, Heidelberg, Leiden, Bologna, Montpellier and Toledo were important centres for the creation and diffusion of knowledge and new ideas that transformed thinking and practice in these cities and wider areas. Other cities derived their growth from trade, or from manufacturing in later centuries. Further, national innovation systems are different and so is their manifestation in cities and regions, whereas cities differ in what they have inherited from the past both in physical shape and structure, and in their social fabric. Even within Europe we observe differences between Western and Eastern European cities, based on legacies from the past (Chapain and Lee, 2009; Burdack and Lange, 2011). Following recent comparative studies by Yigitcanlar (2009), Musterd and Murie (2010) and Van Winden (2010) we highlight various important policy aspects that call for attention and are addressed in the chapters of this volume.

First, the ideas that economic success is related to a city's ability to 
attract the creative class and that 'quality of place' is a key determinant, are widely accepted in local/regional policy-making. Traditional industrial cities have especially embraced this idea as they suffer not only from a legacy of slow-growth manufacturing industries, but linked to that, also from a backdrop of poor urban amenities, culture, quality of (social) housing stock and quality of public space. To reverse the trend, many of these cities have bet on investments in culture, amenities and landmark architecture to help to attract and retain the 'creative class'. However, later research has cast some doubt on part of this policy line. For example, the 'creative class', at least in Europe, turns out to be less mobile and less difficult to retain (Musterd and Murie, 2010). This volume questions some parts of the policies, but mostly for the reasons that such one-sidedness causes an increase in social inequality and diminished social coherence within the city population as negative side-effects, and that there is a lack of clarity on the precise socioeconomic groups and jobs that are to be attracted and retained (Chapters 2, 3 and 4). In addition, Chapter 9 takes up the spatial distribution issues of human capital in European cities.

Second, city and regional governments regard higher education institutes, particularly universities, as sources of growth and prosperity (for example, Shane, 2004). Since the early 1980s, national and local policymakers began to place increasing emphasis on providing incentives for and building on a stronger relationship between universities (or more broadly, higher educational institutes) and business firms. This has led to the emergence of many incubators, science parks and support schemes for knowledge transfer and for young technology-based firms. Most recently, this policy refers to what is now recognized as the 'third task' of universities of bringing new knowledge to market ('valorization'), be it by way of selling patents, development of innovative applications in university spinoff firms, or contract research commissioned by large firms (Huggins and Johnston, 2009; Hussler et al., 2010). An important change seems to be the shift to a model of open innovation, in which various customers play a stronger role than before, in so-called regional testbeds and 'living labs' (Van Geenhuizen, 2011). The major aim of these innovation networks is to connect researchers earlier than before with customers in real-life testing situations, thereby shortening time-to-market. So far, such networks deal mainly with adoption of ICT (information and communication technology) new media and medical sciences (mainly health care), and application of sustainable energy solutions and safety solutions. Increasing the benefits of higher education is a global trend, and is supported by the OECD (2007) in recommending cities and regions to make more of their knowledge base. Issues like these are addressed in Chapter 3 (a critical 
evaluation of city policies), Chapter 6 (new roles of science parks) and Chapter 8 (role of universities in economic and spatial transformation).

While university cities or knowledge cities have been addressed since the early 1980s, attention to urban development based on exploitation of local cultural resources and the centrality of imagination (e.g., UNESCO) only emerged from 2000. This has led to a wave of policies to breed cultural industries, although still weaker compared with universities (Cooke and Lazeretti, 2007; Evans, 2009). Since this development, the concepts of creative cities and knowledge cities have been merged due to the idea of fruitful synergy between cultural activities and knowledge-based activities (Musterd and Deurloo, 2006) indicating that there is ultimately only a difference in emphasis. Policies on the creative sector in cities are taken up in this volume in Chapter 2 (Amsterdam and Rotterdam in the Netherlands) and in Chapter 17 (Shanghai, China).

Third, personal ties have been identified as an important factor in recent research. These ties help to shape knowledge flows (tacit knowledge) and tend to influence location decisions of firms and people (Musterd and Murie, 2010). Personal ties are the source of social capital in the city, which supports young high-tech firms in finding access to resources. However, not all personal networks produce positive social capital; this seems to depend on specific network characteristics, like openness and orientation outside the city/region. This volume pays attention to benefits from personal relations in the context of growth of university spin-off firms (Chapter 10) and in the context of knowledge spillovers and innovation among ICT firms in a clustered setting (Chapter 16). Although personal ties help to shape knowledge flows, other factors are at work as well, like professional networks of specialized knowledge, and communities of practice. How learning takes place depends among others on the sector, dealing with science-based learning, application or problem-based learning, or learning in creative sectors (Asheim et al., 2007; Malecki, 2010). The extent to which spatial proximity and network-based proximity matter in science-based learning is taken up in this volume in Chapter 12, with a focus on biotechnology and cities in the US.

Fourth, several cities invest in landmark architecture and other 'grand projects' to underline their ambitions as a 'knowledge city'. An interesting manifestation of the knowledge turn in urban policy is the trend to link knowledge-based activity to urban planning. An increasing number of cities seek to create or foster 'knowledge quarters' or 'creative quarters' as an integrated part of the urban fabric, or attempt to 're-integrate' campuses at the edge of cities. This trend of 're-urbanization' sharply contrasts with the previous decades, when new campuses and science parks were typically created at 'greenfield' suburban locations, and brings back - be 
it with larger distances than in the past - knowledge-based development to the heart of Europe's cities, reflecting a neo-Schumpeterian view of innovation as an interactive iterative process with multiple actors involved (Van Winden, 2010). Needless to say that many city governments and universities make strong efforts to align their strategies in order to be successful in reaping the fruits of an improved spatial and functional integration. The issue of alignment of city planning and university strategies is taken up in Chapter 5.

The identity or image of a city - recognized as a significant 'soft' location factor for companies and people - is increasingly deployed in marketing and branding techniques to move the city image into the 'right' direction. In their public relations, cities typically seek to associate themselves with knowledge and creativity, thereby stressing the quality of local knowledge assets (number of students, skilled labour force, universities, design schools, etc.). Moreover, events are used to support and sustain the urban image as 'creative knowledge city'. Branding as such is not included in the current volume, but identity and heritage on which this is partly based is included in the case studies of Aachen and Dortmund (Chapter 8) and Shanghai (Chapter 17).

'Hard' factors in location decisions in the knowledge economy have already been put forward by Batten (1995). In addition, Yigitcanlar et al. (2008) draw particular attention to the use of ICT, not only as a factor of connectivity in location decisions but also as a basis for planning and decision support tools, and for e-governance. Thus, despite the emergence of 'soft' factors, 'hard' factors have remained important (Musterd and Murie, 2010). The latter include agglomeration economies; basic infrastructures connecting knowledge cities physically and virtually with cities in the region and around the globe; tax conditions; qualified labour and labour costs; available space (offices, laboratories and incubators), and rent levels. The idea is that these location conditions need to be met at a basic level. Many chapters in this volume take some of these conditions into account, alongside others. 'Hard factors' are relatively strongly emphasized in the analysis of campus development (Chapter 5) and science parks (Chapter 6) and in the analysis of location patterns of advanced producer services (Chapter 13, the city of Munich, and Chapter 15, the city of São Paulo).

As a last point, we mention that while the content of enhancing policies of creative knowledge city development has received much attention, the changes in the concomitant policy approaches and governance models have not. As the creation and use of knowledge have fundamentally changed in the past decade (Nowotny et al., 2001) and continue to change - as indicated by multidisciplinary and network-based structures 
including a large number of actors (particularly customer groups), a diversity of spatial scales and short time duration - a manifold uncertainty has emerged, ranging from dynamic actor complexity in investment in new campuses and city quarters, to lack of knowledge on whether and when the policy measures bring the goal of a more productive and prosperous city nearer. Uncertainty and, at the same time, the pressure to make decisions in a timely manner call for using strategic choice approaches and new leadership models (Stough, 2003; Friend and Hickling, 2005; Gibney et al., 2009). In this volume, leadership issues are not examined, but particular aspects of strategic policy and planning approaches are addressed in relation to campus development (Chapter 5) and science parks (Chapter 6).

\section{STRUCTURE AND SCOPE OF THE BOOK}

In the light of the above observations, there is a clear need for solid conceptual thinking. From the previous analysis, it follows that the creative knowledge city in this volume is approached from various combinations of theoretical angles (Table 1.1). We look at:

- evolutionary approaches, particularly path dependency related, for example, to (past) impacts of industrial revolution;

- 'classic' location theory ('hard' factors);

- cluster theory such as advantages of specialization, supplying and outsourcing, and localized knowledge spillovers;

- network theory (actors) in terms of benefits from proximity and from social capital.

- 'soft' conditions, such as talent and tolerance;

- organizational learning, among firms and city governments, including knowledge transfer processes;

- strategic choice approaches, particularly in dealing with policy uncertainty.

\section{Structure of the Book}

Part I (Critical Views on Policies and Policy Tools) offers various discussions of urban policies concerning the growth of creative knowledge cities. This part connects regional shifts towards the knowledge economy with considerations on urban planning and spatial transformation. The main points of the critics in this part stem from the simple and straightforward use of the city concepts, without sufficient attention to the 
Table 1.1 Approaches to creative knowledge cities in this volume

\begin{tabular}{|c|c|c|}
\hline Theory/Approach & Cities & Empirical Focus \\
\hline 'Soft' conditions & Rotterdam (Chapter 4) & $\begin{array}{l}\text { Importance of middle } \\
\text { class and specific } \\
\text { economic sectors }\end{array}$ \\
\hline \multirow[t]{2}{*}{$\begin{array}{l}\text { Path dependency and } \\
\text { 'soft' conditions }\end{array}$} & $\begin{array}{l}\text { Aachen and Dortmund } \\
\text { (Chapter 8) }\end{array}$ & $\begin{array}{l}\text { Economic restructuring, } \\
\text { identity and image, } \\
\text { triple helix processes }\end{array}$ \\
\hline & $\begin{array}{l}\text { Cities in Hungary } \\
\text { (Chapter } 7)\end{array}$ & $\begin{array}{l}\text { Institutions affecting } \\
\text { academic } \\
\text { entrepreneurship }\end{array}$ \\
\hline \multirow[t]{3}{*}{$\begin{array}{l}\text { 'Classic' location theory } \\
\text { and 'soft' conditions }\end{array}$} & $\begin{array}{l}\text { European cities } \\
\text { (Chapter 9) }\end{array}$ & $\begin{array}{l}\text { Human capital and 'soft' } \\
\text { attributes like tolerance }\end{array}$ \\
\hline & Munich (Chapter 13) & Accommodation/space \\
\hline & $\begin{array}{l}\text { São Paulo, Brazil } \\
\text { (Chapter 15) }\end{array}$ & $\begin{array}{l}\text { and accessibility for } \\
\text { advanced producer } \\
\text { services (APS) }\end{array}$ \\
\hline \multirow[t]{2}{*}{$\begin{array}{l}\text { Cluster approach and } \\
\text { network (personal ties, } \\
\text { social capital) approach }\end{array}$} & $\begin{array}{l}\text { Delft and Trondheim } \\
\text { (Chapter 10) }\end{array}$ & $\begin{array}{l}\text { Benefits from social } \\
\text { capital in personal } \\
\text { networks }\end{array}$ \\
\hline & $\begin{array}{l}\text { Campinas, Brazil } \\
\text { (Chapter 16) }\end{array}$ & $\begin{array}{l}\text { Inter-firm knowledge } \\
\text { spillovers in personal } \\
\text { networks }\end{array}$ \\
\hline $\begin{array}{l}\text { Cluster approach and } \\
\text { 'hard' and 'soft' factors }\end{array}$ & Shanghai (Chapter 17) & $\begin{array}{l}\text { Formation of various } \\
\text { types of creative clusters } \\
\text { by city government }\end{array}$ \\
\hline \multirow[t]{2}{*}{$\begin{array}{l}\text { Network approach } \\
\text { (eventually including } \\
\text { 'hard' factors) }\end{array}$} & Vienna (Chapter 11 ) & $\begin{array}{l}\text { Institutional distance as } \\
\text { barriers in cross-border } \\
\text { firm networks }\end{array}$ \\
\hline & $\begin{array}{l}\text { Cities in the United } \\
\text { States (Chapter } 12 \text { ) }\end{array}$ & $\begin{array}{l}\text { Spatial and network-based } \\
\text { proximity in co- } \\
\text { invention relationships }\end{array}$ \\
\hline $\begin{array}{l}\text { Evolutionary, } \\
\text { organizational learning } \\
\text { in networks }\end{array}$ & $\begin{array}{l}\text { European cities } \\
\text { (Chapter 14) }\end{array}$ & $\begin{array}{l}\text { Learning and policy } \\
\text { knowledge transfer } \\
\text { between city } \\
\text { governments }\end{array}$ \\
\hline \multirow[t]{2}{*}{$\begin{array}{l}\text { Strategic management } \\
\text { approach }\end{array}$} & $\begin{array}{l}\text { Various Netherlands } \\
\text { and European cities } \\
\text { (Chapter 5) }\end{array}$ & $\begin{array}{l}\text { Strategy design for } \\
\text { aligning urban and } \\
\text { university campus } \\
\text { strategies }\end{array}$ \\
\hline & $\begin{array}{l}\text { Cities worldwide, } \\
\text { Leiden as case study } \\
\text { (Chapter } 6 \text { ) }\end{array}$ & $\begin{array}{l}\text { Evaluation method design } \\
\text { of science parks }\end{array}$ \\
\hline
\end{tabular}


specific context. Also, a holistic approach is missing, thereby neglecting, the larger economy and well-being of the urban population other than knowledge workers (social division discourse). Particular critics focus on the selected target residential population and economic sectors in creative knowledge city policies, as well as on perceived academic entrepreneurship. In addition, two chapters illustrate the need for strategic policy/ management approaches in spatial planning, in particular, for campus development and science park development. A path dependence approach is adopted in a chapter on triple helix policies to speed up urban economic transformation.

In Part II (Key Conditions: Human Capital, Networks and 'Soft' Factors) the focus is on conditions influencing knowledge availability and knowledge flows. These include among others educational level of the city population, high-skills employment, tolerance, connectivity of cities through global firm networks; social capital and organizational learning in networks (high-tech firms and city governments); and, network relations facing different types of proximity (in a region, in cross-border areas). The results indicate the simultaneous existence of both local/regional and global networks, but also the influence of institutional distance on establishing short-distance cross-border networks, thus limiting the growth of creative knowledge cities.

In Part III (Creative Knowledge Cities in Emerging Economies) the focus is shifted from the developed world to the emerging economies of Brazil and China. As the creative knowledge city concepts have originated in North America and Europe, the conditions under which creative cities arise in these countries may be different in character, or may face another time pattern and spatial pattern. Attention is given to institutional transferability of the creative knowledge city concept. The conditions taken up in this part include 'hard' location factors, like connectivity of the city in traffic systems, allowing the rise of new hubs and office space for knowledge-based services; an array of 'hard' and 'soft' conditions in creative cluster development; and knowledge spillovers through informal contacts underlying innovation in metropolitan firms.

\section{Part I Critical views on policies and policy tools}

In Chapter 2, Arie Romein and Jan Jacob Trip highlight and criticize the use of the creative city thesis in urban policies. They address the long-term value of this thesis, and identify and characterize eight key elements in creative city development, that is: natural assets, social climate, buzz (atmosphere), labour market, residential environment, amenities, clusters and incubators, and policy-making. Next, the authors discuss two case studies in the Netherlands: Amsterdam and Rotterdam. Contrary to Rotterdam, 
the creative industries in Amsterdam have grown substantially in the past decade. The creative city policies of the two cities, however, do not differ very much in emphasis, target groups and implementation. Businessoriented approaches turn out to be most explicit in these policies, not people-oriented policies. Rotterdam offers a paradox in that the literature focuses on fine-grained diversity in the city, allowing for easy meetings, while in Rotterdam it is the port-city image, the 'rhythm of the river' and anonymity of open spaces that attract architects and designers to settle in the city. In terms of growth potentials, the authors posit that (small-scale) creative industries can become stronger if these are integrated in larger networks (value chains) of high-tech businesses, and are more closely linked to the identity of the city. To reach urban policy goals the authors prefer a more fine-tuned and context-specific policy, but also a holistic policy addressing more general conditions.

In Chapter 3, Ana María Fernández-Maldonado and Arie Romein focus on cities that build the new economy among others upon an important university of technology. They examine two such cities in the Netherlands, Delft and Eindhoven, while elaborating a broad concept of 'sustainability' in urban development, including a sufficient balance between competitiveness of the local economy and meeting the demands for quality of life (place) for all user groups (social inclusion). Delft and Eindhoven turn out to be basically different in business dynamics. Delft has lost manufacturing industry and lacks the profile of Eindhoven as a high-tech industrial node, but its ICT sector is dynamic and growing. Further, Delft is in the southern Randstad, bordering the much larger cities of The Hague and Rotterdam, whereas Eindhoven is the largest city in its region, a situation causing different potentials for knowledge city policy. From a social point of view Delft and Eindhoven are almost identical: a lack of job availability for low-skilled workers and also shortage of social housing for them. The overall conclusion is that knowledge based policies are not inevitably conducive to economically and socially sustainable urban development.

Along the lines of the previous chapters, Marco van der Land presents in Chapter 4 some critical notes on the role assigned to the new middle class and to particular economic sectors in urban knowledge policies, using the city of Rotterdam (the Netherlands) as an example. The empirical analysis reveals that a large share of the new middle class do not live in the city where they work. However, this does not mean that they have no ties with the city that are beneficial for the urban creative milieux. Second, the maritime services sector appears to have a much weaker local orientation than the business services sector. These two policy flaws occur in a policy environment that is geared towards uncritically accepting the 
'dogma' of the knowledge city and neglecting the potentially increasing self-segregation of the middle class for safety, privacy and status reasons. The challenge for knowledge cities like Rotterdam is to combine economic growth with policies that stimulate diversity and equal access to benefits of the knowledge economy, and to look at the knowledge city as part of a comprehensive economic plan.

The next two chapters reflect the need for strategic approaches in spatial planning and policy-making, given pressure from complexity and uncertainty. Alexandra den Heijer, Jackie de Vries and Hans de Jonge take up the need for alignment of city and university strategies in university campuses (Chapter 5). The authors start with the history and policy context of campus development, mainly in the Netherlands, in a context of international trends. They argue that the competitive position of knowledge cities depends to a large extent on the collaboration between urban authorities and knowledge institutions, and focus on the spatial planning and real estate components in this collaboration. Accordingly, they develop a framework for strategic design of collaborative planning in four steps: first, assessing the current situation and opportunities of aligning campuses and cities; second, exploring the changing demand of universities for real estate; third, exploring combined models of future campuses and knowledge cities to take advantage of opportunities; and fourth, assessing implications for a combined urban and campus strategy. The chapter draws on studies of campus development in the Netherlands, and compares the city of Utrecht (the Netherlands) with Munich (Germany). The authors conclude with a discussion of a 'list of campus functions' as a tool to help establish a collective city-university strategic agenda.

In addition, Marina van Geenhuizen, Danny P. Soetanto and Victor Scholten (Chapter 6) focus on impacts from science parks and new needs in evaluation of this policy tool. The authors conclude that science parks are widely different and have produced outcomes that are either not conclusive or in part positive in terms of performance of firms. Particularly, the causality question remains unsolved and proper regional impact studies are in short supply. Despite rather poor proof of success, science parks, paradoxically, remain very popular as a policy tool, a situation that follows from implicit goals and emerging new goals of science parks. The science park paradox suggests the importance of tangible symbols, learning environments and harnessing social capital in a context of largely invisible and uncertain results from knowledge city policies. The authors, therefore, forward a new approach in the evaluation of science parks. Evaluation preferably starts with the identification of the (different) goals and roles of science parks, including implicit 
and shifting ones. The new elements in the proposed approach include a multidimensional (multiple goal) perspective, a process approach emphasizing steps towards reaching goals and an integrative approach including related initiatives. The chapter illustrates the analysis of growth dynamics of on-site firms on the basis of Leiden BioScience Parks in the Netherlands.

In Chapter 7, Katalin Erdös and Attila Varga remind us that the origin of the 'academic entrepreneur' is in the academic system of the United States, and that it seems not unrealistic to use this model in Central European systems, rooted in a continental (German) tradition and affected by centralized socialist tradition. To elucidate this issue, the authors present results of in-depth interviews with university researchers active in firm formation in Hungary. The authors find that 'classical' academic entrepreneurial firms do exist and are spun-off by well-established, internationally recognized scholars with rich academic network connections. Aside from this type of entrepreneur, they identify - mainly based upon different motivations - the 'unbalanced' academic entrepreneur, the one impeded by environmental factors, and the 'externally motivated' academic entrepreneur. Policies commonly applied to motivate academic spin-off formation such as technology transfer activity and science park development seem ineffective. On the contrary, institutional changes in the research system in Hungary would be more effective, like increasing financial autonomy of universities, real competition among academic institutions in attracting highly qualified researchers, and establishment of a multilayer system of research funding.

Further, Martina Fromhold-Eisebith (in Chapter 8) takes up the evolutionary perspective on long-term transformation processes after old industries have collapsed. She elaborates on this perspective in a study of the cities of Aachen and Dortmund (Germany); places that have found a way of exiting from traditional sectors, like coal-mining and textiles, to the excellence of new-technology-oriented activities. The author forwards the paradox of 'heritage-driven progress' referring to a development based on pride of place, high self-esteem and feelings of responsibility, but also on dissociation and dissatisfaction with the industrial situation, which has triggered targeted initiatives for change. Major drivers of this change have emerged from triple helix university-industry-government linkages, with each city-region displaying a specific model of interaction. Economic shifts are, however, still not easy to read from regional statistics. Growing evidence, rather, shows a tendency of the knowledge economy to make an impact on the face of urban space, like a new campus at the edge of the city of Aachen, of which positive impulses remain to be seen. 


\section{Part II Key conditions: human capital, networks and 'soft' factors}

Human capital conditions are addressed in Chapter 9 by Andrea Caragliu, Chiara Del Bo and Peter Nijkamp. Using a novel and comprehensive data set on European cities based on the Urban Audit, the European Values Study and Globalization and World Cities data, the authors highlight various spatio-temporal trends in the endowment, distribution and evolution of urban human capital. The authors identify various dimensions in this concept, namely, formal education, the sector composition of the labour force, employment share of the creative class and tolerance and the presence of international and human capital-intensive firms in cities, and they assess the extent to which disparities in these dimensions affect European cities. However, the authors consent that a complete comparability of indicators cannot be derived, due to different data coverage both across and within data sets. Another problem resides in lack of data on smaller EU cities. The authors have tried to overcome the first problem by maximizing the comparability of data sets using all information available and careful data mining. The conclusion is that the mapping exercise and the accompanying spatial statistical analysis provide an informative picture of Europe's urban human capital stock, but the lack of data on small cities could not be overcome. To solve shortage in statistics it is recommended that Eurostat builds a more comprehensive data system, particularly including small cities.

A network approach is adopted by Danny P. Soetanto, Mozhdeh Taheri and Marina van Geenhuizen (Chapter 10), while focusing on social capital needed by a specific category of urban high-technology small firms: academic spin-off firms. Social capital is a major condition in urban economic growth, because it provides support and access to scarce resources. However, not all networks produce benefits from social capital. In the empirical part, the authors analyse the influence of characteristics of these networks on spin-off firms' growth in two dimensions: employment growth and extension of knowledge gaining abroad. Given some limitations in comparing model estimations, the authors find that networks tend to have a weak influence on growth in knowledge acquisition abroad while they have strong influence on employment growth. Social capital necessary for employment growth is mainly derived from heterogeneity of partners and external orientation (beyond the region), while social capital necessary for crossing borders in knowledge acquisition is mainly derived from frequent face-to-face meetings, suggesting that active social networks on a local/ regional scale are a condition for extending knowledge acquisition abroad. In addition, the quality of social networks becomes important only in later stages of spin-off firms' development when apparently sufficient effort has been devoted to them to produce the social capital needed. 
In Chapter 11, Michaela Trippl also adopts a network approach in the analysis of urban firms, but her focus is stronger on the impact of different types of distance on network formation. The author addresses cooperation between firms in Vienna (Austria) and adjacent cross-border regions (Eastern Centrope). Centrope exhibits sharp internal disparities regarding institutions, prosperity level, economic dynamics, industrial structure, knowledge levels and innovation capabilities, pointing to high levels of functional, cognitive and institutional forms of distance. The empirical study provides modest indications for the rise of new innovation networks; witness a minority of firms employing knowledge links with partners in Centrope. Viennese firms have not created large-scale cross-border linkages because they are already strongly embedded in regional/national innovation and business systems and in interaction with global partners. Notwithstanding spatial proximity to Hungary, the Czech Republic and Slovakia, Viennese firms have not substituted existing international linkages for cross-border ones in adjacent regions, mainly due to institutional distance (law, language, culture and mentality). According to the author, the modest level of knowledge networking might also stem from the way in which Centrope's borders are drawn, excluding Prague and Budapest.

Der-Shiuan Lee and Breandán Ó hUallacháin (Chapter 12) adopt a network approach to picture the position of cities in the United States in co-invention relationships. The authors remind us that regional differences in innovative activity are often explained from the perspective of localized knowledge spillovers, arguing that geographical proximity among actors fosters invention and innovation. However, knowledge production involves an increasing number of actors who connect to non-local partners. The space of knowledge flows functions as a network-based system where knowledge flows circulate around alignments of actors in different and distant places. The focus in this chapter is on the relative importance of 'spatial' compared with 'network-based' proximity on knowledge flows in biotechnology co-invention, revealed by using local and global Moran statistics. Results show that metropolitan co-invention relationships are dissimilar when spatial and network-based dependencies are compared. For example, New York has collaborative links with many biotechnology centres across the country but its strongest ties are to the East Coast areas, while San Francisco's ties are clearly national in scope.

A network approach is also adopted by Alain Thierstein and Stefan Lüthi in a case study of Munich (Chapter 13). Networking among firms in this chapter is, however, not seen as supporting growth and innovation, but as one of the factors shaping the spatial structure of the knowledge city. The aim of the chapter is to empirically investigate the functional polycentric patterns and interlocking networks of advanced 
producer services (APS) and high-tech firms in the Greater Munich area. The conceptual background brings together the location behaviour of multi-branch, multi-location firms with a value chain approach. First, the authors examine how multi-location firms in the knowledge economy develop their intra-firm networks internationally. Second, they establish the partners who these firms have working relationships with along individual value chains, and where these extra-firm linkages are located. The results provide evidence that the Greater Munich area can be regarded as a hierarchically organized polycentric mega-city region, in which a high concentration of intra-firm and extra-firm linkages can be observed.

In Chapter 14, Martin de Jong and Jurian Edelenbos remind us of the important condition that creative and knowledge-based city governments act as learning organizations in city networks; a subject that has received little attention so far. To fill this gap, the authors analyse knowledge exchange among city planners, by highlighting the role of 'transfer agents' as academic and/or policy experts operating in communities in different policy arenas in the exchange process. The study builds on literature on policy transfer and policy learning, and elaborates the idea that policy transfer can be fruitfully approached as a process of knowledge/ information transfer between producers, senders, facilitators and recipients. In a study of the Pegasus Project (launched in 2002 by the European network organization Eurocities), attention is focused on the applicability of the 'ROM approach' (Dutch for Spatial Planning and Environment) as used in Greater Rotterdam to six other European cities: Seville, Malmö, Vienna, Oslo, Birmingham and Genoa. The authors examine the knowledge exchange among these cities by using two mechanisms, that is, social interaction and conceptual replication, and they identify which policy lessons have been transferred between the seven cities, including new insights gained by these cities.

\section{Part III Creative knowledge cities in emerging economies}

Theoretical perspectives are different in this part, but what the chapters have in common is the potential of comparing knowledge cities in different cultures, political systems and urban history, including national economic cycles. Roberto Rocco (Chapter 15) adopts the global cities perspective and takes a closer look at the location of advanced producer services (APS) triggered by urban spatial transformation in the knowledge-based economy of São Paulo. The modern hubs of these activities along the internal ring in this city seem to indicate a new logic where connectivity between nodes is vital. In emerging open systems, the logic of location of advanced services seems to have shifted to the infrastructures enabling the connection of new 'centralities' within complex regional or metropolitan 
urban systems and the connection of existing clusters between themselves. Old central business districts are bound to lose their importance as new more connected 'centralities' emerge where general connectivity is better, but revitalization policies have been in place since the 1980s; this, however, with mixed results. The trends observed in São Paulo may also happen in other metropolitan areas on other continents, but with different spatial scale and time dimensions.

In Chapter 16, Renato Garcia and Veneziano Araujo examine whether the often cited mechanisms underlying urban innovation - knowledge spillovers - are important in the ICT cluster in Campinas in Brazil (the tenth largest city in the country) and whether these compare with the ones in the Aalborg cluster (Denmark). Similar to the Aalborg cluster, a large majority of the employees consider informal knowledge contacts rather important to their work. Despite mostly dealing with general knowledge, these knowledge contacts tend also to include more specific issues such as standardized products and even new products developed by colleagues in other companies, a pattern that is not similar to the Aalborg cluster. There is also a trend that more experienced professionals in the Campinas region have vaster informal contact networks containing more valuable information, and that employees in Brazilian companies tend to value local knowledge sources as more important than do employees in multinational companies. Aside from some main similarities, important differences tend to exist between Campinas and Aalborg, and these probably stem from the different nature of the economic activities involved, that is, a dominance of software development and a dominance of engineering-related activity respectively.

In the final chapter, Yawei Chen takes up the question of transferability of creative city concepts, in particular whether the creative cluster strategy can be transferred from Western cities to Shanghai in China. The author first examines various concepts of creative city policies and then describes four different strategies of creative cluster growth adopted by the Shanghai government, indicating a mix of local bottom-up initiatives and top-down guiding of cluster growth. It appears that room for improvement of Shanghai's creative cluster strategy mainly refers to 'soft' infrastructure aspects, particularly the city's social climate and creative milieu and their influence on growth of creative industries. It is not only the spatial policy context but also the democratic traditions that are different between Western cities and Chinese cities like Shanghai. The author observes that Shanghai finds its own way of adjusting and amending the management of creative industries. This situation refers to general guidelines, regulations, a five-year plan to direct (coordinate) creative industries' development and establishment of platforms and alliances to ensure that creativity can be 
nurtured and transformed into market products, while developing local niches. In doing so, Shanghai has created a different creative industries' agenda compared to other Chinese and Western cities.

\section{RESEARCH AVENUES}

Knowledge-intensive cities and smart creative cities will remain the strategic vehicles for global competition in an open world. The enabling factors for such cities deserve - as argued in the present volume - due attention. Three of these factors, that is, human capital (or put in a different way, the creative class), learning modes and land availability call for specific focus in research. There are two reasons with regard to human capital. First, there is a lack of data on smaller cities meaning that relative shortages in education and so on are not known and understood, which may hamper designing adequate policies (Chapter 9), and second, there is little insight into whether creative knowledge workers (in all cities) behave in reality in the way policy-makers think, like living in 'quality places', a footloose residential behaviour, and being actively involved in social and cultural life of the city (Chapter 4).

Further, learning and its spatial ramifications have largely remained a black box, except for those ways of learning measured by data on collaboration connected to patents. Much knowledge, however, will never be patented because it is not sufficiently new, or patenting is not common for the sector involved. Whether learning is mainly proximity-based or network-based could be measured in other ways, for example, based on collaboration data concerning innovation projects that have received public subsidies. Such understanding is important in choosing an emphasis in policy measures, creating better local/regional learning places or creating better conditions for connecting with partners in other regions/ countries, or both.

Land availability calls for specific attention because some developments indicate decreasing needs, causing implications for spatial planning. The general move to e-learning in standard parts of the curriculum at universities is pointing to decreasing needs for faculty buildings and space on campuses for education (Chapter 5), whereas the rise of 'living labs' may reduce needs for in-company laboratories at business parks in general and science parks specifically (Chapter 6). It is not known how quickly these developments take place and how comprehensive they may be.

Aside from more insight into enabling factors, there is a clear need for benchmarks of various stages in creative knowledge city development over time. Despite the increasing number of cross-national comparative city 
studies, it has remained difficult to derive solid benchmarks (Chapter 8). Benchmarks could be established for different types of cities dependent on their (past) economic structure, like for traditional manufacturing cities and for more service-oriented capital cities, and for larger and smaller cities. A lack of benchmarks concerning knowledge-based performance and enabling factors prevents learning efforts among city governments. However, understanding of enabling factors needs to increase further before solid benchmarks can be established, but also availability of data at adequate spatial scales needs to be extended.

In the remainder of this section, we focus on issues in policy-making. Transferability of the creative knowledge city concept remains an issue in which insights need to be increased, particularly the influence of culture. Aside from China and India, countries in the Arab world are increasingly adopting knowledge city models today. Whether these countries will be successful depends on the extent to which their policies align with local ways of learning and transferring tacit knowledge, and whether these allow for bringing new (technology) knowledge to market. Whether culture and policy traditions match with the ones in North America and Europe remains to be seen, but there could be a unique way, like that identified in the study of Shanghai for China (Chapter 17).

In parallel, governance structures of knowledge clusters - alone or interacting in a network - call for new approaches dependent on the rationales involved (see for example, Laranja et al., 2008; Sørensen and Torfing, 2009). In an ideal model, the new governance or leadership of place embraces a cross-boundary, differentiated, flexible and learningbased mode of governing of actors' multi-level networks, while using integrated and holistic approaches. Cross-boundary, because the knowledge economy itself and its enabling factors are spread over different policy areas; differentiated and flexible, because different networks and knowledge actors are brought together, including their diverse goals and means, and spatial needs and time dimensions; learning-based, because of the need to deal with uncertainty through debate, collaborative learning, monitoring and simulation studies; and integrated and holistic, because of the large variety of interrelated enabling factors and potentially wide areas of impacts and side-effects of policy measures. Another difference from previous models is an increased role for local strategic intelligence in policy design processes.

Leadership is necessary to hold together widely different actors and networks, by creating consensus and sense of urgency of common goals and policy decisions, as well as commitment to implementing these decisions. Governing place in the urban creative knowledge economy is even more complicated if the city is a small one adjacent to large cities, each with 
different economic structures and ambitions; this in contrast to a city that is the single largest in the region (Chapter 3). There is a need to identify models of governance that can make the best of the first situation.

Improving triple helix relations clearly mirrors the complexities and challenges of leadership (Etzkowitz, 2008), and with the shift to more open innovation, complexity is even growing as the number of actors in these relations increases. Leadership might take the form of distributed leadership or collaborative leadership, but in fact theoretically and empirically there is a lack of insights into the best models for governing place under the new circumstances (Gibney et al., 2009, Collinge et al., 2010).

\section{REFERENCES}

Asheim, B.T., L. Coenen and J. Vang (2007), 'Face-to-face, buzz and knowledge bases: socio-spatial implications for learning, innovation and innovation policy', Environment and Planning C, 25 (5) 655-70.

Batten, D. (1995), 'Network cities: creative urban agglomerations for the 21st century', Urban Studies, 32 (2), 313-27.

Burdack, J. and B. Lange (2011), 'Accommodating creative knowledge workers? Empirical evidence from metropoles in Central and Eastern Europe', German Annual of Spatial Research and Policy, 2011, 59-68.

Carrillo, F.J. (ed.) (2006), Knowledge Cities, Approaches, Experiences and Perspectives, Oxford: Elsevier, Butterworth-Heinemann.

Chapain, C. and P. Lee (2009), 'Can we plan the creative knowledge city? Perspectives from Western and Eastern Europe', Built Environment, 35 (2), 157-64.

Collinge, C., J. Gibney and C. Mabey (2010), 'Introduction: leadership and place', Policy Studies, 31 (4), 367-78.

Cooke, P. and L. Lazzeretti (eds) (2007), Creative Cities, Cultural Clusters and Local Economic Development, Cheltenham, UK and Northampton, MA, USA: Edward Elgar.

Evans, G. (2009), 'Creative cities, creative spaces and urban policy', Urban Studies, 46 (5-6), 1003-40.

Etzkowitz, H. (2008), The Triple Helix: University-Industry-Government Innovation in Action, London: Routledge.

Friend, J. and A. Hickling (2005), Planning Under Pressure. The Strategic Choice Approach (3rd edition), Oxford: Elsevier, Butterworth-Heinemann.

Gibney, J., S. Copeland and A. Murie (2009), 'Towards a "new" strategic leadership of place for the knowledge-based economy', Leadership, 5 (1), 5-23.

Huggins, R. and A. Johnston (2009), 'The economic and innovation contribution of universities: a regional perspective', Environment and Planning C: Government and Policy, 27 (6), 1088-106.

Hussler, C., F. Picard and M.F. Tang (2010), 'Taking the ivory from the tower to coat the economic world: regional strategies to make science useful', Technovation, 30 (9-10), 508-18.

Laranja, M., E. Uyarra and K. Flanegan (2008), 'Policies for science, technology 
and innovation. Translating rationales into regional policies in a multilevel setting', Research Policy, 37 (5), 823-35.

Malecki, E. (2010), 'Everywhere? The geography of knowledge', Journal of Regional Science, 50 (1), 493-513.

Musterd, S. and R. Deurloo (2006), 'Amsterdam and the preconditions for a creative knowledge city', Journal of Economic and Social Geography, 97 (1), 80-94.

Musterd, S. and A. Murie (eds) (2010), Making Competitive Cities, Oxford: Wiley-Blackwell.

Nowotny, N., P. Scott and M. Gibbons (2001), Re-Thinking Science. Knowledge and the Public in an Age of Uncertainty, Oxford: Polity.

OECD (2007), Higher Education and Regions: Globally Competitive, Locally Engaged, Paris: OECD.

Shane, S.A. (2004), Academic Entrepreneurship: University Spin-offs and Wealth Creation, Cheltenham, UK and Northampton, MA, USA: Edward Elgar.

Sørenson, E. and J. Torfing (2009), 'Making governance networks effective and democratic through metagovernance', Public Administration, 87 (2), 234-58.

Stough, R. (2003) 'Strategic management of places and policy', The Annals of Regional Science, 37 (2), 179-201.

Van Geenhuizen, M. (2011), 'Knowledge valorization cannot work without being anchored. On the way to more benefits from universities in cities and regions', Delft/The Hague: Delft University of Technology/NICIS Institute (forthcoming).

Van Geenhuizen, M. and P. Nijkamp (2006), 'Learning regions in an evolutionary Context. Policy-making for high technology firms', Int. Journal of Entrepreneurship and Innovation Management, 6 (3), 265-82.

Van Winden, W. (2010), 'Knowledge and the European city', Journal of Economic and Social Geography, 101 (1), 100-107.

Yigitcanlar, T., K. Velibeyoglu and S. Baum (eds) (2008), Creative Urban Regions: Harnessing Urban Technologies to Support Knowledge City Initiatives, Brisbane: Queensland University of Technology.

Yigitcanlar, T. (2009), 'Planning for knowledge-based urban development: global perspectives', Journal of Knowledge Management, 13 (5), 228-42. 
Marina van Geenhuizen and Peter Nijkamp - 9780857932853

Downloaded from PubFactory at 04/26/2023 03:34:25PM 